Discussão e conclusões: Este diagnóstico representa uma raridade dentro dos carcinomas metastáticos, pois nem o tecido glandular nem o palato são frequentemente afetados. Assim, é importante colocar em discussão todos os diagnósticos diferenciais. Um exame clínico e anamnese detalhados representam ferramentas essenciais na formulação do diagnóstico inicial. A análise imunohistoquímica pode ser um recurso adicional no diagnóstico definitivo. Deste modo, a cooperação entre o médico oncologista e o médico dentista é necessária para um tratamento holístico e deteção precoce de manifestações sistémicas e metástases à distância destes pacientes.

http://doi.org/10.24873/j.rpemd.2017.12.035

\#003 Encerramento de diastema através de restauração direta com resina composta

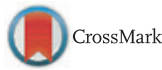

Francisco Ramos*, Diogo Cardoso, António Capelas, Carlos Almeida, Rute Rio

Instituto de Ciências da Saúde, Universidade Católica Portuguesa, Viseu, Portugal

Introdução: Os diastemas correspondem a um espaço presente entre dois dentes contíguos, não havendo ponto de contacto entre os mesmos. Apresentam elevado impacto a nível estético, principalmente quando presentes no segundo sextante, particularmente entre os incisivos centrais superiores. No que concerne ao tratamento, o mesmo pode passar pelo tratamento ortodôntico, reabilitação com recurso a restaurações diretas e indiretas, ou a conjugação de ambos. A escolha do tratamento ideal depende de diversos fatores, tais como a dimensão dos dentes em causa, tamanho do diastema, posição dos dentes e expectativas do paciente.

Descrição do caso clínico: Paciente do género masculino, 25 anos de idade, compareceu na consulta de Dentisteria Operatória, na Clínica Dentária Universitária de Viseu, com preocupações estéticas em relação ao seu sorriso. Apresentava diastema interincisivo (dentes 1.1 e 2.1), e pretendia que este fosse fechado através de um tratamento rápido e económico. Após análise clínica do caso e da sua iconografia foi apresentada a opção do fecho do diastema através de restaurações diretas com resina composta. Foram realizadas impressões e modelos de trabalho, fotografias e enceramento com base na anatomia geral dentária e na obtenção de uma correta proporção dentária. Confecionada a matriz de silicone foi realizado o mock-up. Após ajustes ao enceramento, foi aplicado o isolamento absoluto e a restauração foi realizada com sistema HRI Micerium. Em consulta de controlo foi melhorado o acabamento e polimento.

Discussão e conclusões: A utilização de resina composta no fecho de diastemas pode ser uma solução viável e com bons resultados estéticos e funcionais. A eficácia do tratamento vai depender de vários fatores, sendo os principais a capacidade adesiva, o tamanho do diastema, bem como o tamanho original dos dentes em causa. Para uma excelente adesividade é necessário realizar um protocolo adesivo correto, sendo imprescindível a presença de isolamento absoluto para evitar a presença de fluidos que possam comprometer a adesividade da resina. O tratamento foi realizado com sucesso, apresentando bons resultados estéticos pela mimetização da cor na- tural dos dentes através da resina. A protrusão e o overbite foram fatores tidos em conta, apresentando valores e funcionalidade dentro do normal. Foi conseguido um ótimo feedback por parte do paciente.

http://doi.org/10.24873/j.rpemd.2017.12.036

\section{\#004 Manifestações dentárias na Osteogénese Imperfeita de tipo VIII}

Céu Machado*, Luís Fonseca, Yashad Mussa, Patrícia Caixeirinho, João Martins, Natacha Ribeiro

CHLC Centro Hospitalar de Lisboa Central, EPE

Introdução: A osteogénese imperfeita (OI) é uma entidade nosocomial heterogénea e rara. A sua classificação tem sido reformulada, sendo que o tipo VIII foi mais recentemente reconhecido e do qual podem resultar alterações dentárias.

Descrição de caso clínico: Doente do sexo masculino, 17 anos de idade, caucasiano, com antecedentes de fratura bilateral da anca e fratura da coluna vertebral durante a infância. Submetido a estudo genético diagnóstico de OI de tipo VIII. História dentária pregressa com atraso na esfoliação dos decíduos. É referenciado a consulta de Estomatologia para avaliação prévia ao início de tratamento com bifosfonatos endovenosos (ev). Na anamnese referiu queixas de sensibilidade dentária. No exame objetivo constatou-se baixa estatura, discreta hipoplasia do terço médio da face, escleróticas azuladas, dentes com cor castanho-amarelada generalizada e sem outras lesões. A ortopantomografia revelou dentes com hipoplasia do esmalte e raízes dentárias curtas.

Discussão e conclusões: O tipo VIII tem incidência inferior a $10 \%$ na população de doentes com OI. Sendo um tipo de OI mais recentemente reconhecido, a literatura é escassa na descrição das complicações dentárias associadas. O tratamento inclui bifosfonatos endovenosos (ev), relacionados com complicações em alguns procedimentos dentários. A hipoplasia do esmalte, aumenta o risco de cárie e de outras lesões de perda de estrutura dentária. A OI de tipo VIII é uma forma grave da doença que pode estar associada a aumento do risco de perda de estrutura dentária. O tratamento pode incluir bifosfonatos ev, que condiciona as opções de tratamento. O acompanhamento médico com maior regularidade é importante na manutenção da saúde oral destes doentes.

http://doi.org/10.24873/j.rpemd.2017.12.037

\section{\#005 Trissomia 21 - contributo dos gérmenes dentários no diagnóstico

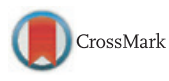

Rosete Nogueira, Inês Sansonetty Côrte-Real, João Marques*, Catarina Varela, Francisco Valente, Paula Vaz

Faculdade de Medicina Dentária da Universidade do Porto; CGC Genetics/Centro de Genética Clínica - Laboratório de Patologia, Unidade de Diagnóstico Pré-Natal, Centro Hospitalar de Vila Nova de Gaia/Espinho

Introdução: A identificação de gérmenes dentários pode ser efetuada através de ultrassonografia fetal e segundo alguns 